\title{
Stent thrombosis in acute coronary syndromes: Patient-related factors and operator-related factors
}

\author{
(D) Martin Kamenik, (D) Petr Widimský
}

Cardiocenter, Third Faculty of Medicine, Charles University and University Hospital Kralovske Vinohrady; Prague-Czech Republic

\section{ABSTRACT}

Objective: Stent thrombosis (ST) is a common phenomenon in acute coronary syndromes (ACS) when compared to stable coronary artery disease. This study analyzed the patient- and operator-related risk factors of ST in ACS.

Methods: Coronary angiograms of 1738 consecutive ACS patients admitted in a large tertiary center between year 2014 and 2016 were analyzed retrospectively for the presence of ST. The paired angiograms [ST in ACS during and after percutaneous coronary intervention (PCI)] of the patients were analyzed by two independent observers, with focus on lesion characteristics and procedure techniques. Clinical and laboratory data were collected.

Results: Stent thrombosis was found in 29 (1.6\%) ACS patients, with a combination of at least one clinical/laboratory risk factor and one lesion/ operator risk factor identified in $28(96 \%)$ out of the 29 ACS patients with ST. The following risk factors for ST were found: Renal insufficiency $(\mathrm{OR}=4.14, \mathrm{p}<0.001,95 \% \mathrm{Cl}=1.73-9.88)$, type 2 diabetes (OR=2.21, $\mathrm{p}=0.034,95 \% \mathrm{Cl}=1.06-4.61)$, excessive alcohol consumption (0R=3.12, $\mathrm{p}=0.023$, $95 \% \mathrm{Cl}=1.17-8.33$ ), stent implantation for ST-elevation myocardial infarction (STEMI) (OR=2.28, $\mathrm{p}=0.029,95 \% \mathrm{Cl}=1.08-4.81$ ), left main (LM) or left anterior descending artery (LAD) as culprit lesion ( $\mathrm{R}=2.80, \mathrm{p}=0.010, \mathrm{Cl} 95 \%=1.27-5.95)$, and absence of antiplatelet therapy prior to $\mathrm{ST}(\mathrm{OR}=3.58$, $\mathrm{p}=0.002,95 \% \mathrm{Cl}=1.60-7.96)$. The following lesion/operator possible risk factors were identified: Bifurcation lesion ( $\mathrm{n}=7$; $24 \%$ ), heavy coronary calcifications $(n=13 ; 44 \%)$, in-stent restenosis with secondary plate rupture $(n=6,20 \%)$, inappropriate stent size selection $(n=6,20 \%)$, and errors in periprocedural drug administration $(n=4,14 \%)$.

Conclusion: ST occurred in 1/62 ACS patients after PCI. A combination of clinical/laboratory and lesion/operator risk factors were present in almost all ACS patients with ST. This finding may support the search for strictly individualized strategies for the treatment of ACS patients with ST after PCI. (Anatol J Cardiol 2020; 24: 274-9)

Keywords: stent thrombosis, risk factors, acute coronary syndrome, antithrombotic treatment

\section{Introduction}

Stent thrombosis (ST) is the most dreadful complication of percutaneous coronary intervention (PCI) (1-3). Over the last two decades, coronary angioplasty with stent implantation has gained a firm position in treating patients with coronary vascular disease (CVD). $\mathrm{PCl}$ is used alongside with cardiovascular surgery, especially in acute coronary syndrome. Although the incidence of ischemic heart disease is on a decline, the absolute number of coronary atherosclerotic patients treated by implantation of stent is on the increase (4). The benefits of the stent implantation used for acute and elective cases of CVD are indisputable (5). Every medical procedure which leaves an artificial device (such as stent implantation) in an organism carries with certain risks (which in this case is stent thrombosis).
Stent thrombosis is the complete occlusion of a coronary vessel in place of previously implanted stent. This situation usually results in ST-elevation myocardial infarction (STEMI) $(6,7)$ with very poor prognosis. Mortality rate of this event was reported as high as $40 \%$ (8). The prevalence of ST in the modern era of drug eluting stent is between 1.1 and $1.9 \%$ (9-12). The clinical risk factors for the development of stent thrombosis are well known.

The previous works on ST suggest acute coronary syndrome as a reason for the stent implantation. However, history of some chronic conditions, vascular dysfunction, and progression of the neoatherosclerosis are the most common risk factors for the development of ST (13-20). In this study we analyzed the clinical, laboratory and operator/lesion characteristics of ACS patients with ST in order to determine the possible risk factors for developing ST.

Address for correspondence: Martin Kamenik, MD, Cardiocenter, Third Faculty of Medicine, Charles University and Faculty Hospital Kralovske Vinohrady, Srobarova 50, Prague-Czech Republic

Phone: +420776573185 E-mail: martinkamenik@gmail.com

Accepted Date: 22.05.2020 Available Online Date: 23.09.2020

(C) Copyright 2020 by Turkish Society of Cardiology - Available online at www.anatoljcardiol.com DOl:10.14744/AnatolJCardiol.2020.69679 


\section{Methods}

Coronary angiograms of 1738 consecutive patients (admitted in large tertiary center between year 2014 and 2016) with acute coronary syndrome (ACS) including ST-elevation myocardial infarction (STEMI), non-ST-elevation myocardial infarction (nonSTEMI) and unstable angina pectoris were analyzed retrospectively for the presence of ST. There were no exclusion criteria. Paired angiograms (First PCl from the time of stent implantation and second PCl at the time of ST) from 29 ACS patients with ST were analyzed by two independent observers, with focus on lesion characteristics and procedure techniques. The stent type, as well as the post-dilatation procedure followed, was based on the discretion of the operator. Clinical and laboratory data collated from a review of patients' charts were included in the analysis. The analyzed patient characteristics were sex, age, presence of diabetes mellitus 2 type, renal insufficiency, arterial hypertension, dyslipidemia, current smoking status, and regular and excessive consumption of alcoholic beverages (defined as more than 1 standard drink per day). Renal insufficiency was defined as the history of chronic kidney disease stage 3. Patients with type 2 diabetes were included, provided that they were on diet or treated orally with anti-diabetic medications or insulin. The analyzed laboratory characteristic (at time the of stent implantation) were hemoglobin level, creatinine level, troponin level and platelet count. Other characteristics studied were reason for stent implantation (initial diagnosis of STEMI), culprit lesion treated with stent in left main (LM) or left anterior descending artery (LAD), and non-usage of anti-aggregation medication before ST. In our study, only ACS patients with angiographic or post-mortem verified occlusions in stented area were included. The acute and late ST were included according to ARC criteria (21). The follow-up mortality data was obtained from the national health insurance registry. The determination of the possible lesion/operator risk factors for ST was done after a detailed review of literature on the topic, and was decided upon by the investigators.

\section{Statistical analysis}

The test for normal distribution of data was by Kolmogorov-Smirnov normality test. Data was expressed as the mean \pm standard deviations. Student's t-test was done to check for differences between two groups of quantitative data. Chisquare or Fisher's exact test was used (where applicable) to check for the differences between groups of categorical data which were expressed as counts and percentages. The importance of risk factors were subjected to univariate logistic regression. $P$ values less than 0.05 were adopted as significant. All statistical analysis was done using IBM SPSS version 23.

\section{Results}

ST was found in $29(1.6 \%)$ of 1738 ACS patients screened. The mortality after two years follow-up was $30 \%$. Two thirds of the
ACS patients with ST were men but were non-significantly different from the women. More than half of the analyzed patients were older than 65 years. The other characteristics which did not differ statistically ( $p>0.05$ ) were history of arterial hypertension, dyslipidemia and smoking. Statistical significant differences were found for renal insufficiency ( $24 \%$ vs. $7 \%, p<0.001)$, type 2 diabetes $(48 \%$ vs. $29 \%, \mathrm{p}=0.034)$, alcohol consumption $(17 \%$ vs. $6 \%, \mathrm{p}=0.023)$, STEMI as reason for stent implantation ( $58 \%$ vs. $36 \%, \mathrm{p}=0.029)$, LM or LAD as a culprit lesion ( $65 \%$ vs. $40 \%, \mathrm{p}=0.010)$ and non-usage of anti-aggregation medications before ST ( $31 \%$ vs. $8 \%, p=0.002$ ). There was a statistical significant difference in the absolute platelet count ( $243 \pm 70$ vs. $273 \pm 75, p=0.005)$. The laboratory levels of creatinine, troponin and hemoglobin between the two groups were non-significant $(p>0.05)$. The summary of these characteristics are shown in Table 1 and 2. The following risk factors for ST were found: renal insufficiency (OR=4.14, $\mathrm{p}<0.001,95 \% \mathrm{Cl}=1.73-9.88$ ), type 2 diabetes $(\mathrm{OR}=2.21, \mathrm{p}=0.034,95 \% \mathrm{Cl}=1.06-4.61)$, excessive alcohol consumption (OR=3.12, $\mathrm{p}=0.023,95 \% \mathrm{Cl}=1.17-8.33)$, stent implantation for STEMI (OR=2.28, $\mathrm{p}=0.029,95 \% \mathrm{Cl}=1.08-4.81$ ), $\mathrm{LM}$ or $L A D$ as culprit lesion $(\mathrm{OR}=2.80, \mathrm{p}=0.010,95 \% \mathrm{Cl}=1.27-5.95)$, and non-usage of anti-aggregation medications before ST (OR $=3.58$, $\mathrm{p}=0.002,95 \% \mathrm{Cl}=1.60-7.96)$. Overview of the risk factors is in Table 3. The average length of hospital stay for the group with ST $(6.9 \pm 2.7$ days) was non-significantly ( $p=0.20)$ different from that of the control group $(5.14 \pm 3.43$ days).

The stents in the ST were $19.07 \pm 6.02 \mathrm{~mm}$ in length, with the nominal diameter of $3.32 \pm 0.44 \mathrm{~mm}$. There was no significant $(p>0.05)$ difference between the nominal diameter and the real diameter after stent implantation. The most frequent stent types used were metallic stents (BMS, 27\%) and drug-eluting stents of second generation with everolimus (EES, 24\%). The various stent types are shown in Table 4. There were no first generation DES or bioresorbable stents with ST in our study. Post-dilatation was used only in two patients (6\%) in the ST group. An average of $1.62 \pm 0.55$ stent was implanted per patient in the ST group, and this was significantly different $(p<0.001)$ from that of the control group (1.15 \pm 0.11 ). A suboptimal result of stenting procedure was more often documented for patients in the ST group [3 $(10 \%)$ vs. $54(3 \%), p=0.02]$.

The possible lesion/operator risk factors of ST can be divided into several parts. The lesion related factors were bifurcation lesion $(n=7 ; 24 \%)$, heavy coronary calcifications $(n=13 ; 44 \%)$, instent restenosis with secondary plate rupture and ST $(n=6,20 \%)$. Operator related factors were wrong stent size selection (diameter under-sizing or incomplete lesion coverage) $(n=6,20 \%)$, and errors in periprocedural drug administration $(n=4,14 \%)$. The patient-related factor errors in the use of anti-aggregation medications was identified as responsible for ST in 3 patients while the other factors were identified in 4 patients. An overview of the lesion/operator risk factors is shown in Figure 1. A combination of at least one clinical/laboratory risk factor and one lesion/ operator risk factor was identified in $28(96 \%)$ out of the 29 ACS patients with ST. 
Table 1. Basic clinical characteristics

\begin{tabular}{|lccc|}
\hline & Without stent thrombosis, $\mathbf{n}(\%)$ & With stent thrombosis, $\mathbf{n}(\%)$ & $P$-value \\
\hline Male sex & $1205(70)$ & $24(82)$ & 0.157 \\
Age above 65 years & $1013(59)$ & $17(58)$ & 0.619 \\
Type 2 diabetes & $\mathbf{5 0 7 ( 3 0 )}$ & $\mathbf{1 4}(\mathbf{4 8 )}$ & $\mathbf{0 . 0 3 4}$ \\
Chronic kidney disease & $\mathbf{1 2 2}(\mathbf{7})$ & $\mathbf{7}(24)$ & $<\mathbf{0 . 0 0 1}$ \\
Arterial hypertension & $1096(64)$ & $17(59)$ & 0.540 \\
Dyslipidemia & $567(33)$ & $13(45)$ & 0.191 \\
Active smoking & $878(51)$ & $13(45)$ & 0.485 \\
Alcohol abuse & $\mathbf{1 0 7}(\mathbf{6})$ & $\mathbf{5 ( 1 7 )}$ & $\mathbf{0 . 0 2 3}$ \\
STEMI as an indication for the initial PCI & $\mathbf{6 5 4 ( 3 8 )}$ & $\mathbf{1 7}(58)$ & $\mathbf{0 . 0 2 9}$ \\
LM or LAD as culprit vessel & $\mathbf{6 9 8}(\mathbf{4 1 )}$ & $\mathbf{1 9}(65)$ & $\mathbf{0 . 0 1 0}$ \\
Absence of antiplatelet therapy prior to ST & $\mathbf{1 9 1 ( 1 1 )}$ & $\mathbf{9 ( 3 1 )}$ & $\mathbf{0 . 0 0 2}$ \\
Total & $1709(100)$ & $29(100)$ & \\
\hline LM - left main; LAD - left anterior descending artery & & &
\end{tabular}

Table 2. Basic laboratory characteristics

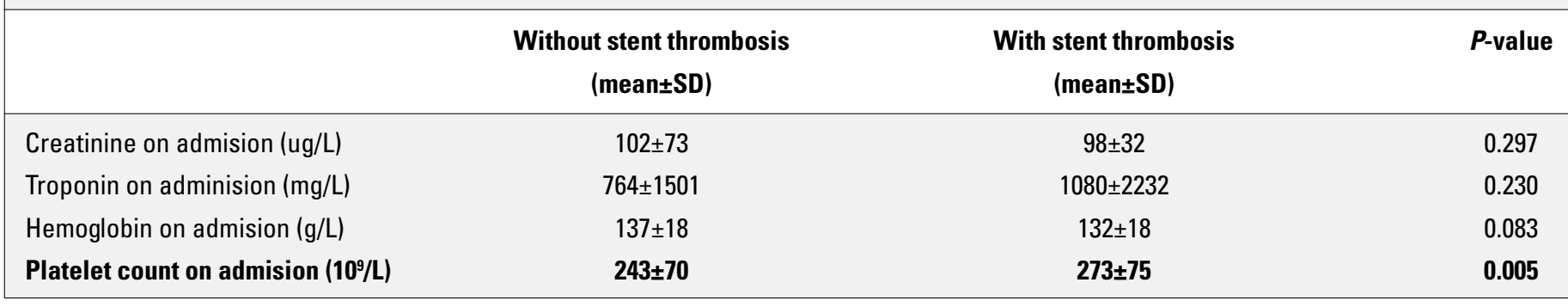

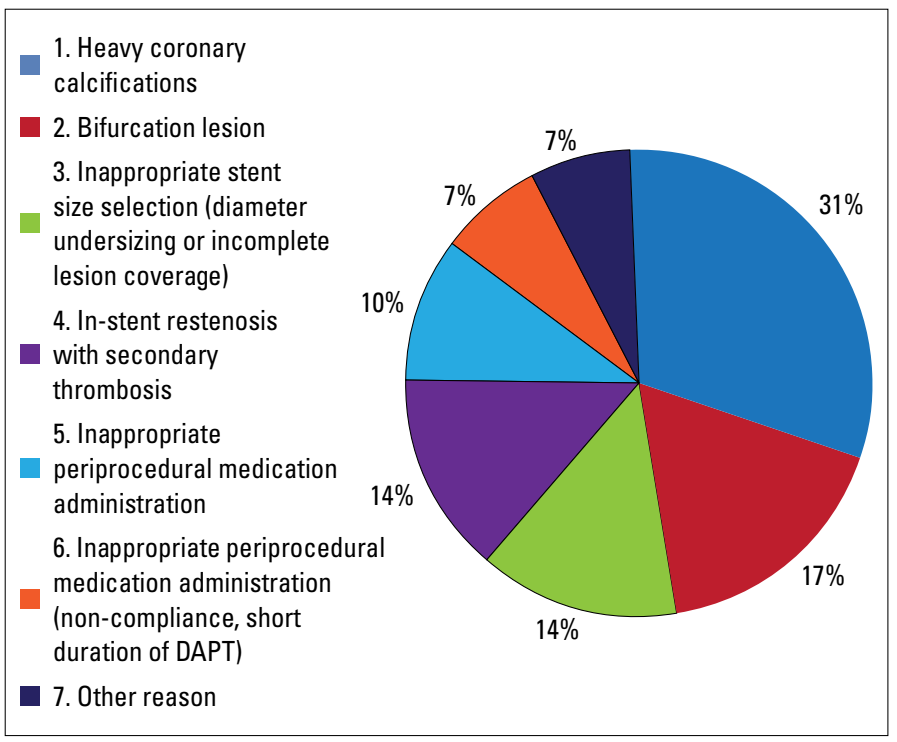

Figure 1. The possible lesion/operator risk factors of ST

\section{Discussion}

The main findings of this study is as follows: (1) the mortality rate of ST in our study was in consonant with that of other stud- ies (22-24); (2) We identified possible lesion/operator risk factors, which are imminent threat of ST, in all patients with ST; (3) the risk of ST was much higher when several risk factors were combined. Despite the technology advancements in stent design and improved antiplatelet therapy, there is an increase in mortality rate of ST patients. As the number of patients treated by $\mathrm{PCl}$ increases, there is corresponding increase in the absolute count of the patients who are endangered. The risk factors can be divided into several categories which are characteristics of the patient, lesion characteristics and procedure outcome (25). Our results, considering the patient related risk factors, revealed statistical significant occurrence of stent thrombosis among patients with diabetes mellitus and renal impairment. Similar results have been demonstrated in a study conducted by Tada et al. (26) and lakovou et al. (27). Excessive alcohol consumption is not frequently described as a risk factor in literature. In 2004, a study on alcoholic consumption and restenosis revealed a lower restenosis rate in patients consuming higher amounts of alcohol (28). The difference in the pathophysiology between restenosis and ST substantiates the findings in our study. The lesion characteristics, significant risk for ACS STEMI as a reason for stenting, and culprit lesion in LM or LAD (29) are not less important. The proposed mechanisms for this finding are malapposition, 
Table 3. Risk factors for stent thrombosis

\begin{tabular}{|lccc|}
\hline Risk factor & Odds ratio & $\boldsymbol{P}$-value & 95\% Confidence interval \\
\hline Male sex & 2.75 & 0.157 & $0.76-5.29$ \\
Age above 65 years & 0.83 & 0.619 & $0.41-1.70$ \\
Type 2 diabetes & $\mathbf{2 . 2 1}$ & $\mathbf{0 . 0 3 4}$ & $\mathbf{1 . 0 6 - 4 . 6 1}$ \\
Chronic kidney disease & $\mathbf{4 . 1 4}$ & $\mathbf{0 . 0 0 1}$ & $\mathbf{1 . 7 3 - 9 . 8 8}$ \\
Arterial hypertension & 0.79 & 0.540 & $0.37-1.67$ \\
Dyslipidemia & 1.64 & 0.191 & $0.78-3.43$ \\
Active smoking & 0.76 & 0.485 & $0.37-1.61$ \\
Alcohol abuse & $\mathbf{3 . 1 2}$ & $\mathbf{0 . 0 2 3}$ & $\mathbf{1 . 1 7 - 8 . 3 3}$ \\
STEMI as an indication for the initial PCI & $\mathbf{2 . 2 8}$ & $\mathbf{0 . 0 2 9}$ & $\mathbf{1 . 0 8 - 4 . 8 1}$ \\
Left main or LAD as culprit vessel & $\mathbf{2 . 7 5}$ & $\mathbf{0 . 0 1}$ & $\mathbf{1 . 2 7 - 5 . 9 5}$ \\
Absence of antiplatelet therapy prior to ST & $\mathbf{3 . 5 8}$ & $\mathbf{0 . 0 0 2}$ & $\mathbf{1 . 6 0 - 7 . 9 6}$ \\
\hline LAD - left anterior descending artery; PCI - percutaneous coronary intervention & & \\
\hline
\end{tabular}

Table 4. Stent types with ST

\begin{tabular}{|lc|}
\hline Stent type & $\mathbf{n}(\%)$ \\
\hline Everolimus eluting stent & $7(24)$ \\
Zotarolimus eluting stent & $5(17)$ \\
Biolimus eluting stent & $5(17)$ \\
Sirolimus eluting stent & $3(10)$ \\
Other type drug eluting stent & $1(3)$ \\
Bare metal stent & $8(27)$ \\
\hline
\end{tabular}

and stent struts crossing an ostial side branch (30). In addition, there were significantly more suboptimal results from index stent implantation, as well as more stents implanted per patient. This suggest that the complexity of the procedure itself plays a crucial role in ST. Similar findings was reported by Lüscher et al. (31). The percentage of patients who were subjected to postdilatation was only $6 \%$ in ST group. The need for post-dilation to achieve optimal stent diameter was demonstrated in POSTIT trial. Its positive effect on lowering the rate of ST has also been demonstrated. The heavy calcification and bifurcation lesion as a lesion related risk factors have been well documented $(32$, 33). The German authors have demonstrated that a decreased stent symmetry in calcified lesions predisposes to mallaposition of the stent (34). This pathologic findings have suggested that the arterial branch points are predisposed to the development of atherosclerotic plaque and thrombus because they are foci with shear stress (35). The next objects of interest are the stents themselves. The diameter of struts, biocompatibility of polymer containing drug which delays the endothelization, thus preventing restenosis, are important technical characteristics which could influence the development of ST. The dynamics of release of this drug is an important variable that affects the outcome of the procedure significantly (36). In this study, there were only second generation DES and BMS in the non-randomized setting. We didn't analyze the rate of stent thrombosis between the stent types because DES and BMS were used in the ratio of 2:1. The last set of factors which can predispose to ST is the periprocedural technique of implantation, and the medication given to the patient during and after coronary intervention. Inappropriate stent size selection (diameter under-sizing or incomplete lesion coverage) was identified as the third most frequent predisposing factor for ST. Poorly conducted peri- and post procedural medication (mainly wrong dosage of heparin or non-usage of antiplatelet therapy during or few hours after stent implantation) was identified in $14 \%$ of patients with ST. Noncompliance in the usage of dual antiplatelet therapy is a well-known risk factor for ST. The absence of any antiplatelet therapy (ASA or P2Y12 inhibitors) predisposes to statistically higher rate of ST (37). In this study, the risk of ST after discontinuing the antiplatelet therapy was almost four times higher. The importance of patient compliance is therefore imminent. Finally, the combination of risk factors rather than only one, may probably be responsible for the complex events seen in the ST patients in our study. A combination of at least one clinical/laboratory and one lesion/operator risk factor was identified in $28(96 \%)$ out of the 29 patients with ST. This finding suggests that the development of ST is influenced by multiple factors on the side of the patient as well on the side of the operator.

\section{Study limitations}

The observational study is by nature selectively bias. The stent type and length were in a non-randomized setting, and was solely the choice of the interventional cardiologist. We did not conduct any advanced visualization for the lesions. On the other hand, the visualization of every implanted stent by IVUS or OCT is inapplicable to conventional or real-life clinical practice, and not 
even for patients who are unstable during procedure. Therefore, the review of angiograms was often only guided during by the interventional cardiologist.

\section{Conclusion}

Stent thrombosis occurred in 1/62 ACS patients after PCI. A combination of clinical/laboratory and lesion/operator risk factors were present in almost all ACS patients with ST. This finding may support the search for strictly individualized strategies for the treatment of ACS patients with ST after PCI.

\section{Conflict of interest: None declared.}

Peer-review: Externally peer-reviewed.

Authorship contributions: Concept - M.K., P.W.; Design - M.K., P.W.; Supervision - M.K., P.W.; Fundings - M.K., P.W.; Materials - None; Data collection and/or processing - M.K.; Analysis and/or interpretation M.K., P.W.; Literature search - M.K.; Writing - M.K., P.W.; Critical review - M.K., P.W.

\section{References}

1. Cutlip DE, Baim DS, Ho KK, Popma JJ, Lansky AJ, Cohen DJ, et al. Stent thrombosis in the modern era: a pooled analysis of multicenter coronary stent clinical trials. Circulation 2001; 103: 1967-71.

2. Holmes DR Jr, Kereiakes DJ, Garg S, Serruys PW, Dehmer GJ, Ellis SG, et al. Stent thrombosis. J Am Coll Cardiol 2010; 56: 1357-65.

3. Claessen BE, Henriques JP, Jaffer FA, Mehran R, Piek JJ, Dangas GD. Stent thrombosis: a clinical perspective. JACC Cardiovasc Interv 2014; 7: 1081-92. [CrossRef]

4. Aggarwal A, Srivastava S, Velmurugan M. Newer perspectives of coronary artery disease in young. World $\mathrm{J}$ Cardiol 2016; 8: 728-34.

5. Sigwart U, Puel J, Mirkovitch V, Joffre F, Kappenberger L. Intravascular stents to prevent occlusion and restenosis after transluminal angioplasty. N Engl J Med 1987; 316: 701-6. [CrossRef]

6. Seto AH, Kern MJ. Early stent thrombosis: Nearly gone, but never forgotten. Catheter Cardiovasc Interv 2018; 91: 849-50. [CrossRef]

7. Ergelen M, Gorgulu S, Uyarel H, Norgaz T, Aksu H, Ayhan E, et al. The outcome of primary percutaneous coronary intervention for stent thrombosis causing ST-elevation myocardial infarction. Am Heart J 2010; 159: 672-6. [CrossRef]

8. Ge J, Yu H, Li J. Acute Coronary Stent Thrombosis in Modern Era: Etiology, Treatment, and Prognosis. Cardiology 2017; 137: 246-55.

9. Inglessis I, Elmariah S, Rengifo-Moreno PA, Margey R, O'Callaghan C, Cruz-Gonzalez I, et al. Long-term experience and outcomes with transcatheter closure of patent foramen ovale. JACC Cardiovasc Interv 2013; 6: 1176-83. [CrossRef]

10. Kukreja N, Onuma Y, Garcia-Garcia HM, Daemen J, van Domburg R, Serruys PW; Interventional Cardiologists of the Thoraxcenter (2000 to 2005). The risk of stent thrombosis in patients with acute coronary syndromes treated with bare-metal and drug-eluting stents. JACC Cardiovasc Interv 2009; 2: 534-41. [CrossRef]

11. Ergelen M, Uyarel H, Osmonov D, Ayhan E, Akkaya E, Soylu 0, et al. Early stent thrombosis in patients undergoing primary coro- nary stenting for acute myocardial infarction: incidence, a simple risk score, and prognosis. Clin Appl Thromb Hemost 2010; 16: 3341. [CrossRef]

12. Daemen J, Wenaweser $\mathrm{P}$, Tsuchida K, Abrecht L, Vaina S, Morger $C$, et al. Early and late coronary stent thrombosis of sirolimuseluting and paclitaxel-eluting stents in routine clinical practice: data from a large two-institutional cohort study. Lancet 2007; 369: 667-78. [CrossRef]

13. Godschalk TC, Gimbel ME, Nolet WW, van Kessel DJ, Amoroso G, Dewilde WJ, et al. A clinical risk score to identify patients at high risk of very late stent thrombosis. J Interv Cardiol 2018; 31: 159-69.

14. Mrdovic I, Savic L, Lasica R, Krljanac G, Asanin M, Brdar N, et al. Usefulness of the RISK-PCI score to predict stent thrombosis in patients treated with primary percutaneous coronary intervention for ST-segment elevation myocardial infarction: a substudy of the RISK-PCI trial. Heart Vessels 2013; 28: 424-33. [CrossRef]

15. Yadav M, Généreux P, Palmerini T, Caixeta A, Madhavan MV, Xu K et al. SYNTAX score and the risk of stent thrombosis after percutaneous coronary intervention in patients with non-ST-segment elevation acute coronary syndromes: an ACUITY trial substudy. Catheter Cardiovasc Interv 2015; 85: 1-10. [CrossRef]

16. Loh JP, Pendyala LK, Kitabata H, Torguson R, Omar A, Minha S, et al. Comparison of outcomes after percutaneous coronary intervention among different coronary subsets (stable and unstable angina pectoris and ST-segment and non-ST-segment myocardial infarction). Am J Cardiol 2014; 113: 1794-801. [CrossRef]

17. Hokimoto S, Tabata N, Yamanaga K, Sueta D, Akasaka T, Tsujita K, et al. Prevalence of coronary macro- and micro-vascular dysfunctions after drug-eluting stent implantation without in-stent restenosis. Int J Cardiol 2016; 222: 185-94. [CrossRef]

18. Borovac JA, D'Amario D, Vergallo R, Porto I, Bisignani A, Galli M, et al. Neoatherosclerosis after drug-eluting stent implantation: a novel clinical and therapeutic challenge. Eur Heart J Cardiovasc Pharmacother 2019; 5: 105-16. [CrossRef]

19. Joner M, Finn AV, Farb A, Mont EK, Kolodgie FD, Ladich E, et al. Pathology of drug-eluting stents in humans: delayed healing and late thrombotic risk. J Am Coll Cardiol 2006; 48: 193-202. [CrossRef]

20. Guo N, Maehara A, Mintz GS, He Y, Xu K, Wu X, et al. Incidence, mechanisms, predictors, and clinical impact of acute and late stent malapposition after primary intervention in patients with acute myocardial infarction: an intravascular ultrasound substudy of the Harmonizing Outcomes with Revascularization and Stents in Acute Myocardial Infarction (HORIZONS-AMI) trial. Circulation 2010; 122: 1077-84. [CrossRef]

21. Cutlip DE, Windecker S, Mehran R, Boam A, Cohen DJ, van Es GA et al.; Academic Research Consortium. Clinical end points in coronary stent trials: a case for standardized definitions. Circulation 2007; 115: 2344-51. [CrossRef]

22. Clemmensen P, Wiberg S, Van't Hof A, Deliargyris EN, Coste P, Ten Berg J, et al. Acute stent thrombosis after primary percutaneous coronary intervention: insights from the EUROMAX trial (European Ambulance Acute Coronary Syndrome Angiography). JACC Cardiovasc Interv 2015; 8(1 Pt B): 214-20. [CrossRef]

23. Heestermans $A A$, van Werkum JW, Zwart $B$, van der Heyden JA, Kelder JC, Breet $\mathrm{NJ}$, et al. Acute and subacute stent thrombosis after primary percutaneous coronary intervention for ST-segment elevation myocardial infarction: incidence, predictors and clinical outcome. J Thromb Haemost 2010; 8: 2385-93. [CrossRef]

24. D'Ascenzo F, Bollati M, Clementi F, Castagno D, Lagerqvist $B$, de la Torre Hernandez JM, et al. Incidence and predictors of coronary 
stent thrombosis: evidence from an international collaborative meta-analysis including 30 studies, 221,066 patients, and 4276 thromboses. Int J Cardiol 2013; 167: 575-84. [CrossRef]

25. Lim S, Koh YS, Kim PJ, Kim HY, Park CS, Lee JM, et al. Incidence, Implications, and Predictors of Stent Thrombosis in Acute Myocardial Infarction. Am J Cardiol 2016; 117: 1562-8. [CrossRef]

26. Tada T, Byrne RA, Simunovic I, King LA, Cassese S, Joner M, et al. Risk of stent thrombosis among bare-metal stents, first-generation drug-eluting stents, and second-generation drug-eluting stents: results from a registry of 18,334 patients. JACC Cardiovasc Interv 2013; 6: 1267-74. [CrossRef]

27. Iakovou I, Schmidt T, Bonizzoni E, Ge L, Sangiorgi GM, Stankovic $G$, et al. Incidence, predictors, and outcome of thrombosis after successful implantation of drug-eluting stents. JAMA 2005; 293: 2126-30. [CrossRef]

28. Niroomand F, Hauer 0, Tiefenbacher CP, Katus HA, Kuebler W. Influence of alcohol consumption on restenosis rate after percutaneous transluminal coronary angioplasty and stent implantation. Heart 2004; 90: 1189-93. [CrossRef]

29. Kuramitsu S, Ohya M, Shinozaki T, Otake H, Horie K, Kawamoto $H$, et al. Risk Factors and Long-Term Clinical Outcomes of SecondGeneration Drug-Eluting Stent Thrombosis. Circ Cardiovasc Interv 2019; 12: e007822. [CrossRef]

30. Mori H, Torii S, Harari E, Jinnouchi H, Brauman R, Smith S, et al. Pathological mechanisms of left main stent failure. Int $\mathrm{J}$ Cardiol 2018; 263: 9-16. [CrossRef]
31. Lüscher TF, Steffel J, Eberli FR, Joner M, Nakazawa G, Tanner FC, et al. Drug-eluting stent and coronary thrombosis: biological mechanisms and clinical implications. Circulation 2007; 115: 1051-8.

32. Tasal A, Bacaksiz A, Vatankulu MA, Turfan M, Erdogan E, Sonmez 0 , et al. Is postdilatation with a noncompliant balloon necessary after coronary stent deployment during primary angioplasty? J Interv Cardiol 2013; 26: 325-31. [CrossRef]

33. Brodie BR, Cooper C, Jones M, Fitzgerald P, Cummins F; Postdilatation Clinical Compartative Study (POSTIT) Investigators. Is adjunctive balloon postdilatation necessary after coronary stent deployment? Final results from the POSTIT trial. Catheter Cardiovasc Interv 2003; 59: 184-92. [CrossRef]

34. Henneke KH, Regar E, König A, Werner F, Klauss V, Metz J, et al. Impact of target lesion calcification on coronary stent expansion after rotational atherectomy. Am Heart J 1999; 137: 93-9. [CrossRef]

35. Iakovou I, Kadota K, Papamentzelopoulos S, Pavlides G, Mitsudo K. Is there a higher risk of stent thrombosis in bifurcation lesion or is it related to the technique? Eurolntervention 2010; 6 Suppl J: J107-11.

36. Torrado J, Buckley L, Durán A, Trujillo P, Toldo S, Valle Raleigh J, et al. Restenosis, Stent Thrombosis, and Bleeding Complications: Navigating Between Scylla and Charybdis. J Am Coll Cardiol 2018; 71: 1676-95. [CrossRef]

37. Sorrentino S, Giustino G, Baber U, Sartori S, Cohen DJ, Henry TD, et al. Dual Antiplatelet Therapy Cessation and Adverse Events After DrugEluting Stent Implantation in Patients at High Risk for Atherothrombosis (from the PARIS Registry). Am J Cardiol 2018; 122: 1638-46. 